\title{
Portuguese Parents' Perceptions of Transdisciplinary Play-based Assessment
}

Manuela Sanches-Ferreira, Toni Linder, Pedro Lopes-dos-Santos, Mónica Silveira-Maia \& Sílvia Alves

\begin{abstract}
An important development in the world of global education is the call for greater inclusion and support for children and students with disabilities. In this article, the authors describe their use of one tool-the Transdisciplinary Play-Based Assessment-to determine children's developmental progress and provide support to parents in helping their children thrive. One important thread we can see throughout this theme issue is the emphasis on community and familial involvement in child care and education. It is no longer accepted practice to silo family time, community time, and school time. Educators, families, and policymakers alike should consider the child in a holistic way that promotes healthy, happy development in all areas.
\end{abstract}

Contemporary practices in early childhood intervention build upon the premise that providing supports and resources to strengthen family competencies is key to enhancing young children's opportunities for learning and development. This view echoes fundamental assumptions of transactional models, which frame human development as the result of complex and dynamic relationships between the individual and the contextual systems. With this as a theoretical foundation, the focus of assessment has transitioned from the description of within-child processes toward the observation of interactions between the child and the environment with the main purpose of collecting information about: 1) what children can do and what they are ready to do, and 2) which environmental factors are acting as barriers or facilitators for children's growth and learning.

According to Bagnato (2007) and Bagnato, Neisworth, and Pretti-Frontczak (2010) professional standards for assessment of ECCE must reflect eight critical qualities: 1) acceptability, or the worth or appropriateness of the scales item content as perceived by parents or caregivers; 2) authenticity, providing information that describes how children function in their natural environments; 3) collaboration, involving professionals and parents in a partnership from 
assessment to intervention; 4) evidence-based development and field testing of the assessment on a wide range of children, including those with disabilities, for the purpose of intervention; 5) convergent data collected across methods, sources, settings, and occasions; 6) sensitivity, providing developmental sequences and observations that can differentiate small increments of progress; 7) universality, or using content, materials, and methods that match children's developmental levels and individual differences; and 8) utility, or treatment validity, of the scale for planning and evaluating interventions.

Despite these principles stressed as fundamentals upon which to base best practices, many assessment measures are still conducted primarily through restrictive methods and styles that favor inauthentic and contrived developmental tasks (Bagnato, Neisworth, \& Munson, 1997 Bagnato, S. J., Neisworth, J. T., \& Munson, S. M. (1997). LINKing assessment and early intervention: An authentic curriculum-based approach (3rd ed.). Baltimore, MD: Paul Brookes.). Moreover, it is still common for professionals from different disciplines to conduct independent assessments using test kits with norms based solely on typical children for the purpose of documenting deficits. What is needed instead is a more authentic assessment process that allows professionals and families to obtain a comprehensive portrayal of the child's range of functioning, including strengths and learning style (Bagnato et al., 1997) Integrated, holistic models are viewed as most practical, useful, and accurate for young children (Bagnato, Goins, Pretti-Frontczak, \& Neisworth; Losardo \& Notari Syverson, 2011; Neisworth \& Bagnato, 2005 )

The Transdisciplinary Play-Based Assessment (TPBA) developed by Linder (1993 Linder, T. W. (1993)(2008)) assumes that children's play is an interactive and natural activity that involves all the developmental domains. Children are motivated to explore, solve problems, engage, and communicate. The child is assessed during play activities by a transdisciplinary team-including the parents-that simultaneously looks at what the child is already doing and what he or she is able to do with support. Parents' participation is fundamental to this model, which recognizes that parents know their children best and that the children are most likely to interact in a natural manner with their families. This article describes the TPBA and provides a strong rationale for its use to ensure ECCE quality. 


\section{A CULTURALLY RESPONSIVE APPROACH}

Transdisciplinary Play-based Assessment (TPBA) (Linder, 1990, 2008) is an authentic approach to examining the skill level and qualitative aspects of a child's development, in addition to children's learning strengths and needs. The approach is useful for children from birth to 6 years of age who are suspected of having a disability or developmental delay due to genetic, biological, environmental, or other risk factors. In addition to determining the need for support services, the TPBA process is also useful for examining the type of intervention that will most benefit the child and for planning intervention objectives and strategies.

The TPBA process involves a team of professionals, typically a psychologist, speech pathologist, occupational and/or physical therapist, and potentially other professionals, including a teacher, social worker, nurse, and/or vision specialist. The team obtains preliminary information from the family relating to the child's developmental, social, educational, and treatment history; the family's routines; and the primary caregivers' perceptions of the child's skills and behaviors. This information is then used to plan a play session with the child and family members. The play session is conducted in the home, community, school, or play clinic setting.

The team observes the child playing with a variety of toys and materials, beginning with those that are preferred by and, thus, motivating to the child. The structure of the play session, the materials used, and the involvement of family members vary depending on the assessment questions, the child's needs, and the family's wishes. During the hour-long session, the child engages in play with a Play Facilitator, siblings and/or peers, parents, other family members, and/or a teacher. Play Facilitators typically use facilitation strategies aimed at enhancing play activities within the children's zone of proximal development (Vygotsky, 1978 Vygotsky, L. S. (1978). The team uses observation guidelines and age tables from Transdisciplinary Play-based Assessment-2nd edition (TPBA2; Linder, 2008 Linder, T. W. (2008) to determine the qualitative aspects of the child's behaviors and skills, in addition to the quantitative skill level of the child's performance. When the parents are not involved in play with the child, they sit with a Family Facilitator and observe the play. The Family Facilitator explains what the team is observing in play, asks about how the child's skills and behaviors compare to what family members see at home, seeks parental help in interpreting the child's communication and behavior, and obtains any other relevant information the family wants to share. The parents are considered part of the TPBA team and their information is integrated into the total picture of the child. After the 
play session, the team meets to have a transdisciplinary discussion of their observations, compare their notes and interpretations, and determine the need for services and supports for the child and family. A comprehensive, integrated report is then written by the team.

\section{Figure 1 Parents' Perceptions of the TPBA2 Session}

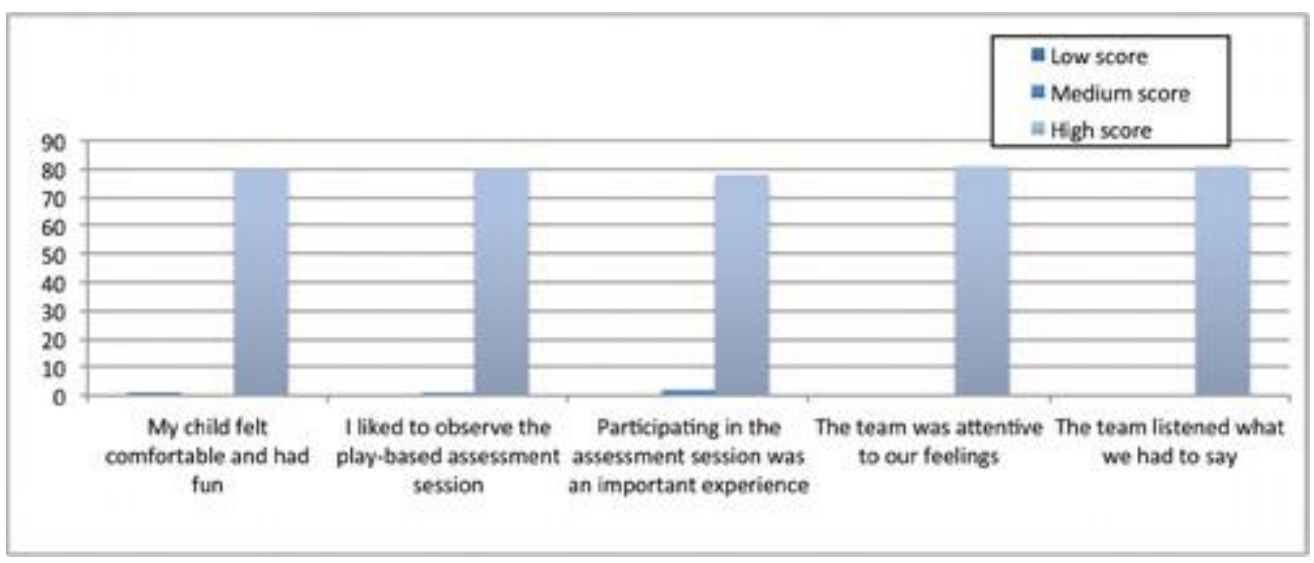

The flexible nature of TPBA2 makes it useful across cultures. Toys, materials, parental involvement, and setting all can be modified to adapt to cultural differences. As TPBA2 is not standardized, professionals from the child's culture can address language differences and other cultural behaviors. Interpretation of age level skills is modified as needed based on informed clinical opinions of the professionals involved and available cultural norms.

\section{SOCIAL VALIDITY IN PORTUGAL}

Previous studies on TPBA in the United States found evidence supporting several dimensions of validity, including criterion-related/concurrent validity (DeBruin, 2005 DeBruin, K. A. (2005); Friedli, 1994 Friedli, C. (1994); Kelly-Vance \& Ryalls, 2008 Kelly-Vance, L., \& Ryalls, B. O. (2008); Linder \& Linas, 2009 Linder, T., \& Linas, K. (2009); content and construct validity (Linder, 2008 Linder, T. W. (2008); Linder, Goldberg, \& Goldberg, 2007 Linder, T., Goldberg, D., \& Goldberg, M. (2007). ); social validity (Myers, McBride, \& Peterson, 1996 Myers, C. L., McBride, S. L., \& Peterson, C. A. (1996); and reliability (Friedli, 1994 Friedli, C. (1994); Linder, 2008 Linder, T. W. (2008). Researchers and practitioners also have argued that early childhood assessment and intervention have not paid enough attention to social validity. Social validity refers to the 
evaluative feedback from consumers about a specific intervention, which in this case corresponds to the perceived value of assessment information and procedures. This commonly involves asking consumers-parents, professionals, or even children-to rate the acceptability, accuracy, and utility of assessments. This article presents how parents in Portugal validated the TPBA2 assessment method.

The Support Unit for Inclusive Schools (UAEI), part of the Department of Special Education within the School of Education from Polytechnic Institute of Porto in Porto, Portugal, provides assessment services to the community. The UAEI assessment team received training in the TPBA2 model and began to use this model at their clinic to assess children referred for evaluation for potential disabilities. As part of their evaluation of TPBA2's effectiveness for Portuguese children, parents of children evaluated at the clinic were asked to complete a questionnaire about their assessment experiences.

\section{Figure 2 Parents' Perception of the Report}

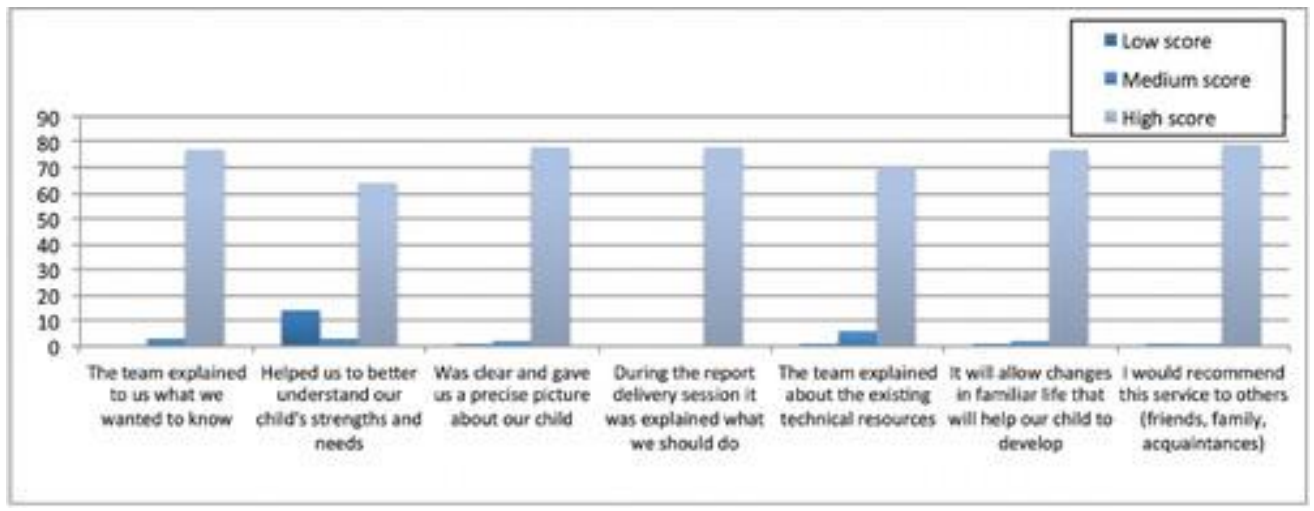

\section{METHOD}

\section{Participants}

Using TPBA2, 122 children between birth and 6 years were assessed. The primary reasons for referral were: cognitive $(37.7 \%, n=46)$; emotional and social $(24.6 \%, n=30)$; language and communication $(19.7 \%, \mathrm{n}=24)$; sensorimotor $(13.9 \%, \mathrm{n}=17)$; and all of the above domains $(4.1 \%, n=5)$. During a meeting to deliver the TPBA report, parents received the satisfaction questionnaire about the TPBA2 process with a stamped envelope. The purpose of the 
questionnaire was explained and parents were asked to return it without any personal identification in order to maintain the integrity of this process.

Of the total 122 parents, 88 completed the anonymous questionnaire, a $72 \%$ return. Thirty-eight parents (43\%) had children who were formerly assessed through traditional assessment approaches. These parents with children already assessed by traditional approaches also were asked, on a separate part of the questionnaire, to compare TPBA2 with the previous assessment. Previous assessment approaches noted by parents included such standardized tests and inventories as the Battelle Developmental Inventory (Newborg, 2004 Newborg, J. (2004), the Griffiths Mental Development Scales (Griffiths, 2006 Griffiths, R. (2006), the Wechsler Preschool and Primary Scale of Intelligence (Wechsler, 2003 Wechsler, D. (2003), and the Schedule of Growing Skills (Bellman, Lingam, \& Aukett, 2007 Bellman, M., Lingam, S., \& Aukett, A. (2007).

\section{Survey Content}

The post-assessment questionnaire addressed parents' perceptions about the assessment process and procedures with regard to two distinct elements of TPBA2, the assessment session and the TPBA report. The questionnaire contains 12 items, rated on a 3-point Likert-type scale ( 1 = disagree; 2 = neutral; 3 = agree). Specifically, parents were asked about their child's level of comfort and enjoyment, the parent's pleasure in observing and participating in the assessment, and their feelings about the team's ability to listen to them and attend to their feelings. Parents were also asked about the information they received from the assessment. They were asked if the team gave them needed or useful information in a comprehensible way, if the team explained their child's strengths and needs well and in a clear and concise way, if parents were given information about useful follow-up interventions and resources, and whether they would recommend the TPBA2 approach to others. 
Figure 3 Parents' Perceptions of TPBA2 Compared to Previous Assessment

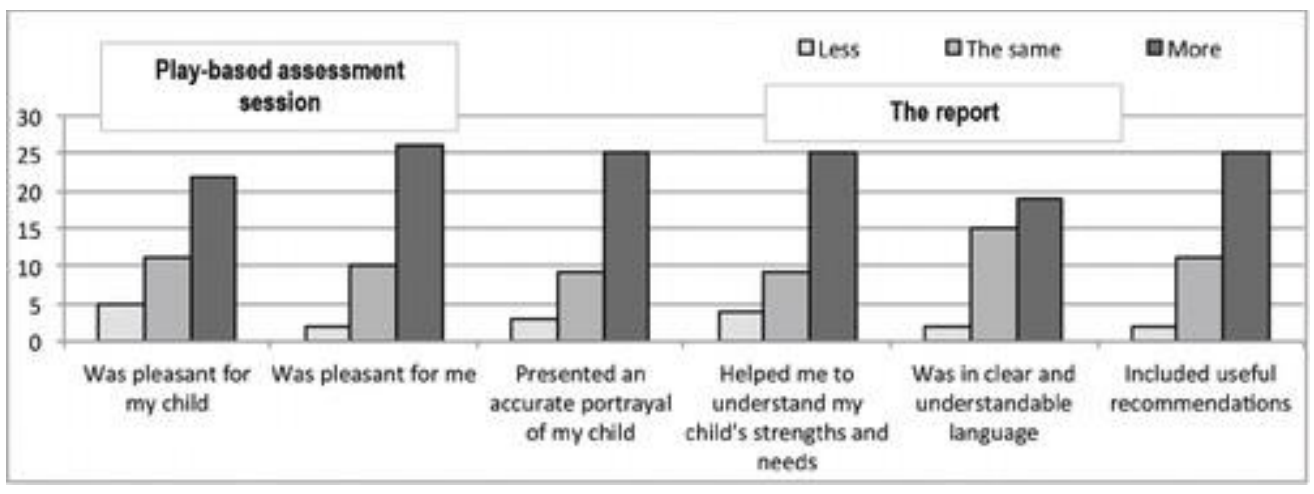

In addition, parents who had previous evaluations were also asked to compare TPBA2 with their other evaluations based on how pleasurable the process was for the child and parents, how accurate the portrayal of the child was, the ability of the assessment to clarify the child's strengths and needs in a clear and understandable way, and the usefulness of the recommendations. Ratings were provided on a 3-point Likert-type scale ( $1=$ less, 2 = the same, $3=$ more). Parents returned the questionnaire in a pre-addressed, stamped envelope.

\section{FINDINGS}

Parents almost unanimously viewed the TPBA2 process positively, both with regard to the assessment session (Figure 1) and the TPBA report (Figure 2). Concerning the assessment sessions, the data showed $98 \%$ of parents and $99 \%$ of the children were comfortable during the TPBA2 session. Also, parents overwhelmingly found the team to be attentive to their feelings, worries, and expectations. Parents also found the report and feedback session with the team to be highly valuable.

Relating to the TPBA report, 96\% percent of parents considered the team's explanation to be useful and desirable. All parents reported that the team explained what they should do at home to support their child's development, and $91 \%$ indicated that the team also explained the existing resources. When asked if the report was clear and gave them a precise picture about their child, $96 \%$ agreed and $79 \%$ considered that the discussion during the delivery of the TPBA report helped them to better understand their child's strengths and needs. As for the report's usefulness, $96 \%$ of parents indicated that the recommendations included in the report may lead 
to changes in family life that would help them support their child's development. Finally, the majority of parents (98\%) reported they would recommend this service to others.

Additional data from the 38 parents whose children had been previously assessed with traditional approaches are presented in Figure 3. Specifically, parents reported to what extent they consider the TPBA session as more pleasurable and informative than the traditional approaches. They considered that the TPBA2 assessment session was more pleasant for them (68\%) and for their child (58\%), and the report presented a more accurate portrayal of their child (68\%), helping them to better understand strengths and needs (66\%). The item with lowest score concerned the language used in TPBA2 sessions and the report; $53 \%$ of parents revealed that it was more clear and understandable than the one used the previous assessment experience, but $46 \%$ did not identify any difference. Parents rated TPBA2 higher on all dimensions when compared to traditional approaches.

\section{CONCLUSION}

In recent years, researchers and practitioners have been exploring new approaches to build child assessment models for young children that are more developmentally appropriate. Evaluation of assessment methods has expanded beyond traditional analyses of psychometric properties to encompass analyses related with congruency of assessment procedures, functionality, and usefulness of results. Therefore, new concepts such as treatment validity, cultural validity, or social validity have become relevant notions to describe and evaluate assessment methods. Although not a formal study, this study presents evaluation data on the social validity of the TPBA2 in a European country. The TPBA2 process incorporates the best practice foundations of being acceptable, authentic, collaborative, evidence-based, convergent, sensitive, universal, and demonstrating utility or treatment validity. Although the social validity of the TPBA2 has been demonstrated in the United States, this study revealed applicability and benefits of the TPBA2 process in Portugal. Studies in other countries are now needed to examine more universal social validity. 


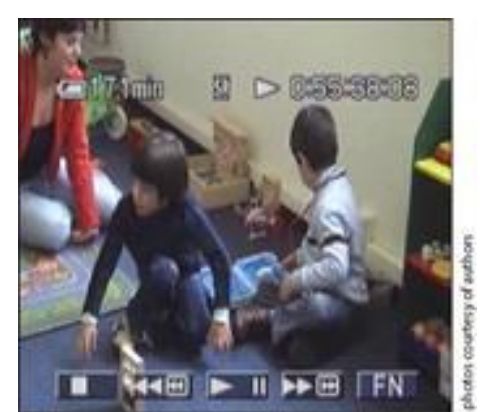

Videotaping is recoermended for later swieve.

Here, sifling and the parent are otoerved in plas:

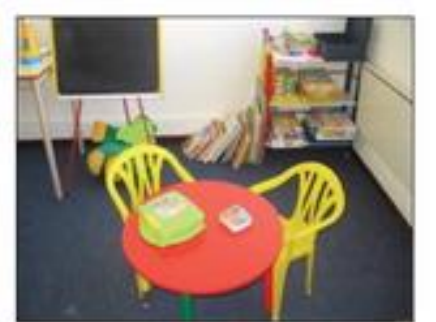

The play environument includes altemative

dramatic play materiale, munipulative toys

books, sencorimetor play equipatent games.

and a wide range of play optione.

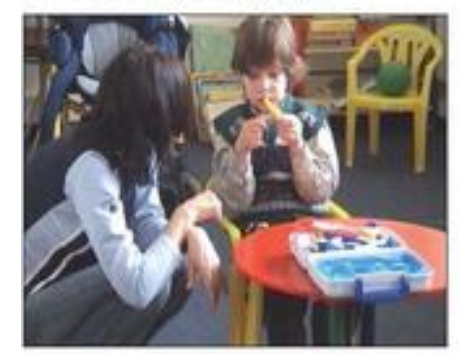

Play with a doctor lat is mone fun than a puper-and. pencil test. 


\section{References}

Bagnato, S. J. (2007). Authentic assessment for early childhood intervention: Best practices. New York, NY: Guilford.

Bagnato, S. J., Goins, D. D., Pretti-Frontczak, K., \& Neisworth, J. T. (2014). Authentic assessment as "best practice" for early childhood intervention: National consumer social validity research. Topics in Early Childhood Special Education, 34(2), 116-127.[Crossref], [Web of Science ${ }^{\circledR}$ ], , Bagnato, S. J., Neisworth, J. T., \& Munson, S. M. (1997). LINKing assessment and early intervention: An authentic curriculum-based approach (3rd ed.). Baltimore, MD: Paul Brookes.

Bagnato, S. J., Neisworth, J. T., \& Pretti-Frontczak, K. (2010). LINKing authentic assessment and early childhood intervention: Best measures for best practices (4th ed.). Baltimore, MD: Paul Brookes.

Bellman, M., Lingam, S., \& Aukett, A. (2007). Schedule of growing skills [Escala de avaliação das competências no desenvolvimento infantil] (M. Machado, Portuguese adaptation). Lisbon, Portugal: Cegoc.

DeBruin, K. A. (2005). A validation study of TPBA-R with the BDI-2. Unpublished doctoral dissertation, University of Denver, Colorado.

Friedli, C. (1994). Transdisciplinary Play-based Assessment: A study of reliability and validity. Unpublished doctoral dissertation, University of Colorado at Boulder.

Griffiths, R. (2006). Griffiths Mental Development Scales [Escala de Desenvolvimento Mental de Griffiths] (P. Borges, I. P. Costa, C. T. Ferreira, I. Gil, I. Carvalhão, S. Fernandes, \& M. Veríssimo, Portuguese adaptation). Lisbon, Portugal: Cegoc.

Kelly-Vance, L., \& Ryalls, B. O. (2008). Best practices in play assessment and intervention. In J. Grimes \& A. Thomas (Eds.), Best practices in school psychology V (vol. 2, pp. 549-559). Bethesda, MD: National Association of School Psychologists.

Linder, T. W. (1993). Transdisciplinary Play-Based Assessment: A functional approach to working with young children (rev. ed.). Baltimore, MD: Paul H. Brooks.

Linder, T. W. (2008). Transdisciplinary Play-Based Assessment (2nd ed.). Baltimore, MD: Paul H. Brooks. 
Linder, T., Goldberg, D., \& Goldberg, M. (2007). Validity of the content and construct of transdisciplinary play-based assessment. Unpublished manuscript.

Linder, T., \& Linas, K. (2009). A functional, holistic approach to developmental assessment through play: The transdisciplinary play-based assessment, second edition. Zero to Three 30(1), 28-33.

Losardo, A., \& Notari Syverson, A. (2011). Alternative approaches to assessing young children (2nd ed.). Baltimore, MD: Paul H. Brookes.

Myers, C. L., McBride, S. L., \& Peterson, C. A. (1996). Transdisciplinary play-based assessment in early childhood special education: An examination of social validity. Topics in Early Childhood Special Education, 16, 102-126.[Crossref], [Web of Science ${ }^{\circledR}$ ], ,

Neisworth, J. T., \& Bagnato, S. J. (2005). Recommended practices: Assessment. In S. Sandall, M. L. Hemmeter, B. J. Smith, \& M. E. McLean (Eds.), DEC recommended practices: A comprehensive guide for practical application in early intervention/early childhood special education (pp. 4569). Longmont, CO: Sopris West.

Newborg, J. (2004). Battelle Developmental Inventory [BATTELLE - Inventário de Desenvolvimento Battelle]. Lisbon, Portugal: Cegoc.

Vygotsky, L. S. (1978). Mind in society: The development of higher psychological processes. Cambridge, MA: Harvard University Press.

Wechsler, D. (2003). Wechsler Preschool and Primary Scale of Intelligence [Escala de Inteligência de Wechsler para a idade pré-escolar]. (M. J. Santos \& M. Simões, Portuguese adaptation). Lisbon, Portugal: Cegoc. 